International Journal of Health Sciences
Available online at www.sciencescholar.us
Vol. 5 No. 3, December 2021, pages: $531-541$
e-ISSN: 2550-696X, p-ISSN: $2550-6978$
https://doi.org/10.53730/ijhs.v5n3.2270

\title{
Neurodynamic Predictors the Effectiveness of Cognitive Activity of Students Ensuring Healthy Lifestyle
}

\author{
Natalya Belousova a, Olga Shefer ${ }^{b}$, Maria Semenova c, Victor Maltsev d, Tatiana Lebedeva e, \\ Yuliya Korchemkina ${ }^{f}$
}

Manuscript submitted: 05 July 2021, Manuscript revised: 09 October 2021, Accepted for publication: 18 November 2021

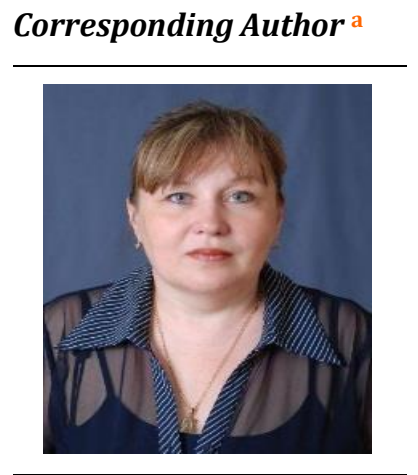

Keywords

cognitive activity; health quality; health risks; healthy lifestyle; neurodynamic predictors; rotating nursing; visual-motor response;

\begin{abstract}
The paper presents the results of the assessment of neurodynamic characteristics and correlation of cognitive activity parameters of students with individual neurodynamic characteristics following the criteria of Sustainable Development Goal 3 "Good health and well-being" (SDG 3). The study was conducted in a cohort of female students aged 17-19 (n=111) of the South Ural State Humanitarian Pedagogical University during the inter-sessional period. Diagnostics of neurodynamic characteristics of students was carried out using the hardware and software complex "NS-pSychoTest". Descriptive statistical analysis of data and correlation analysis were carried out in the environment of Statistica v. 7.0. The results of sensorimotor response presented in the article reflect the optimal level of adaptive regulation of the cerebral component of activity in the majority of the surveyed pedagogical university students in the conditions of their educational and professional activities, which is reflected in the relative stability of cerebral processes with average functional mobility and the optimal level of neurophysiological regulation of CNS activity in the conditions of sensory interference of the students of the cohort of the survey. The paper reveals the interrelationships of neurodynamic indicators with various characteristics of cognitive testing, which indicates the success of the development of educational programs.
\end{abstract}

International Journal of Health Sciences (C) 2021.

This is an open access article under the CC BY-NC-ND license (https://creativecommons.org/licenses/by-nc-nd/4.0/).

a South Ural State Humanitarian Pedagogical University, Chelyabinsk, Russia

b South Ural State Humanitarian Pedagogical University, Chelyabinsk, Russia

c South Ural State Humanitarian Pedagogical University, Chelyabinsk, Russia

d Surgut State Pedagogical University, Surgut, Russia

e South Ural State Humanitarian Pedagogical University, Chelyabinsk, Russia

f South Ural State Humanitarian Pedagogical University, Chelyabinsk, Russia 


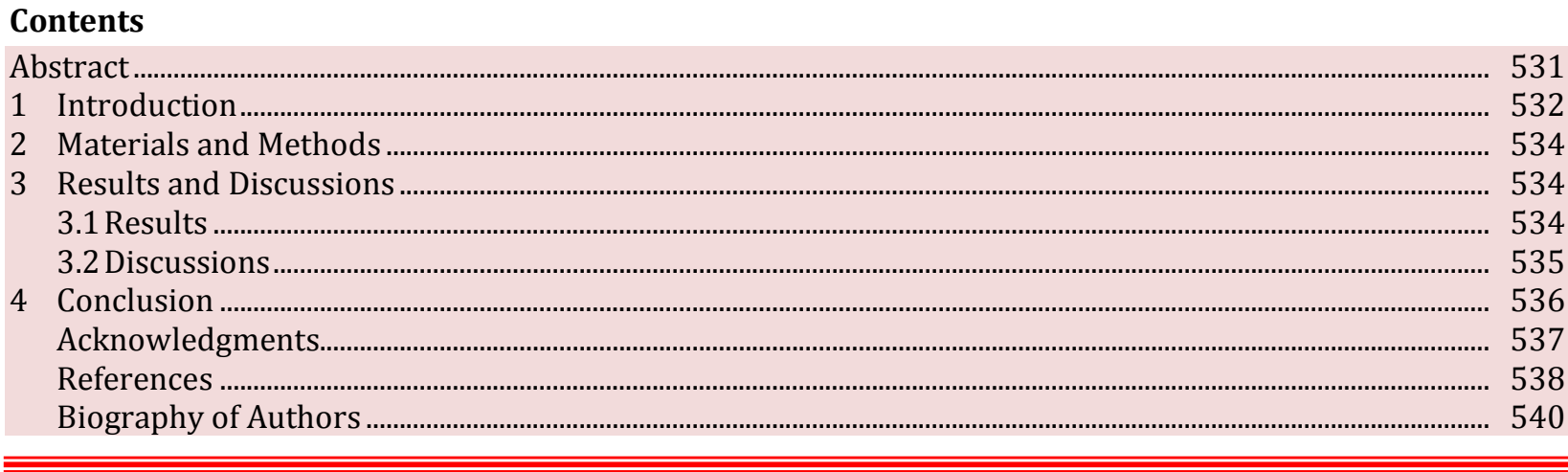

\section{Introduction}

Sustainable Development Goal (SDG) 3, related to ensuring a healthy lifestyle and promoting well-being for everyone at any age. It is one of the Sustainable Development Goals proclaimed by the UN for the period up to 2030. SDG 3 significantly expands the Millennium Development Goals in ensuring a healthy lifestyle and promoting well-being for all at any age - important components of sustainable development (Riebe et al., 2003; King et al., 2007). Combining these aspects into one goal is an important step towards solving the task of building the capacity of all countries in the field of early warning, risk reduction, and management of national and global health risks. Therefore, SDG 3 is an important factor in the way to a sustainable future of using the neurocognitive aspects of education (Benson et al., 2020).

The relevance of the problem of neurodynamic determinacy of individual differences in cognitive activity of students is determined by one of the most important tasks of the modern educational system - the search for ways to improve the effectiveness of learning (Ahmadi \& Tani, 2017). The study of psychophysiological patterns in the formation of individual variations of cognitive activity of students at various stages of ontogenesis (Andrews et al., 2011). This is a condition for solving the problems of developing innovative technologies to improve the quality of the educational process.

Numerous studies have been devoted to theoretical and empirical developments of the problem of the cognitive foundations of individual differences in the academic success of school-age children (Bayguzhin \& Pracheva, 2014; Litvinova, 2008; Tikhomirova, 2016). Difficulties in studying the psychophysiological foundations (including cognitive ones) of academic success are due to the lack of a unified approach to the analysis of results, the "fragmentation" of methodological tools, age and socio-cultural differentiation of the surveyed contingent, and other reasons.

In has been developed of T.N. Tikhomirova, a conceptual structural and functional model based on individual differences and academic success. In this model, the indicators of information processing speed, working memory, sense of number, and nonverbal intelligence were determined as elements of the cognitive basis of academic success. At the same time, the author notes the lability, variability at various stages of development, integrative and probabilistic nature of the assessment of the cognitive foundations of academic success. In addition, the author also notes the need to take into account environmental factors when assessing individual psychological characteristics (Tikhomirova, 2016).

Cognitive activity can be defined in general terms as activity in the process of cognition, the ability to perceive and process external information. Manifestations of cognitive activity are a set of mental processes (perception, attention, memory, thinking, imagination, speech, emotions) and mental states (beliefs, desires, intentions) of a person. In the Western scientific school, cognitive activity is interpreted as behavior caused by cognitive (cognitive) reasons (McLaughlin et al., 2007; Lachman et al., 2010).

Various parameters of cognitive activity as a complex psychophysiological phenomenon are caused by numerous factors. So at present, a large number of studies are devoted to the study of the interrelationships of cognitive functions and physical activity due to the property of neuroplasticity (Hötting \& Röder, 2013). In particular, increased neurogenesis, synaptogenesis, angiogenesis, and neurotrophin release have been shown as neural mechanisms mediating pronounced behavioral cognitive effects of physical exertion (Laidra et al., 2007). 
The category of "behavior effectiveness" in the literature is considered in the context of the theory of organization and management. Within the framework of this approach, the behavior of an individual is understood as a socially conditioned activity, which has natural prerequisites. The behavior of an individual (PI) can be described by the simplified formula Pi = f (I, E), where I is the individual characteristics of the subject, his innate properties, and characteristics, and $E$ is the environment surrounding the individual in which the process of his socialization takes place. The behavior of an individual is characterized by causality, purposefulness, motivation, and measurability of the observed characteristics. According to the National Standard of the Russian Federation quality Management System (GOST R ISO 9000-2015), "efficiency" is interpreted as the ratio between the achieved result and the resources used. Successful, "effective" functioning of an individual in various spheres of life is determined, in particular, by his ability to arbitrarily regulate cognitive processes, to rebuild cognitive activity in connection with changing environmental conditions. It can also be called "cognitive adaptation", "cognitive reorganization" (Bidzan-Bluma \& Lipowska, 2018).

Numerous works are devoted to the study of individualization of the educational process, taking into account stable neurodynamic features and the nature of psychophysiological states, as one of the fundamental conditions for improving the effectiveness and quality of educational interaction (Kraineva \& Shefer, 2017; Merlin, 2005). In this context, neuropedagogy has become widespread. Neuropedagogy is the science of a differentiated approach to learning, taking into account the psychophysiological and neuropsychological characteristics of a student and a teacher or the "genophenotypic" characteristics of students (Bidzan-Bluma \& Lipowska, 2018; Khikmatullaeva et al., 2021).

The multifunctionality of neurodynamic features and the versatility of their influence on various spheres of personality has been shown in numerous studies since the middle of the XX century (Bidzan-Bluma \& Lipowska, 2018; Kraineva \& Shefer, 2017; Maltsev, 2018). A broad retrospective review of domestic studies devoted to the interrelationships of neurodynamic properties with the peculiarities of cognitive processes, some special abilities, and other areas of personality is presented in the works of E.P. Ilyin. The author presents the results of research by N.V. Makarenko, according to which individual differences in the functions of perception, attention, and thinking are largely determined by the level of functional mobility of nervous processes. People with high and average rates of mobility of nervous processes have a higher efficiency of perception and thinking, a higher level of ability to operate with spatial objects, concentrate, and switch attention faster (unlike people with low mobility characteristics). These psychophysiological functions and functional mobility of nervous processes are provided by neurophysiological mechanisms alone. The concentration of attention, according to L.B. Ermolaev-Tomin, N.S. Utkina is better in people with a strong nervous system, and attention switching (when set to work at a free pace) is better in people with a weak nervous system (Mantrova, 2008; Chang et al., 2020). According to V.P. Umnov, when introducing instructions to work as quickly as possible, the advantage in switching attention goes to people with a strong nervous system. The concentration of attention also depends on the balance of nervous processes (in persons with a predominance of arousal, it is greater according to the "external" balance). According to the same auth ors, the text is remembered better by persons with a weak nervous system, and visual objects are remembered better by persons with a strong nervous system. M.N. Ilyina's research has shown that the inertia of arousal is associated with such a strong-willed quality as "patience", which manifests itself in a person's ability to work without reducing intensity, despite developing fatigue, or other difficulties. The connection of rigidity - lability of installations with mobility - the inertia of nervous processes was shown in the works of N.E. Vysotskaya (Maltsev \& Suyundikova, 2019).

It is generally accepted that the influence of these properties on the success and effectiveness of a particular activity, including cognitive, can be realized through the impact on cognitive processes. It can also be implemented through the formation of certain functional states in various situations. Differential psychophysiological features of students determine their functional resources and the ability to show optimal performance in the conditions of educational and professional activity. These features meet the specified requirements of reliability and efficiency of this work and also determine the formation of individual styles of self-regulation of cognitive activity (Kraineva \& Shefer, 2017; Widana et al., 2021).

At the same time, it should be noted that the effectiveness of the activity, including cognitive, as well as the features of adaptation, depends on a set of features of neurodynamic properties that mutually affect each other, as well as on many personal characteristics, intellectual development, motivation and other factors (Kholodnaya \& Khazova, 2017). In connection with the above, the search for neurodynamic correlates of

Belousova, N., Shefer, O., Semenova, M., Maltsev, V., Lebedeva, T., \& Korchemkina, Y. (2021). Neurodynamic predictors the effectiveness of cognitive activity of students ensuring healthy lifestyle. International Journal of Health 
effective cognitive activity of students and, in general, differential psychophysiological analysis of human cognitive behavior is an urgent task.

\section{Materials and Methods}

111 students aged 17-19 of the South Ural State Humanitarian Pedagogical University took part in our study voluntarily during the inter-sessional period. Determination of neurodynamic characteristics of the examined cohort of students was carried out using the hardware and software complex "NS-pSychoTest" ("Neurosoft", Russia, Certificate of Conformity No. ROSS RU.IM18.D00567). The following methods were used in the examination: "Simple visual-motor reaction" (PZMR) to assess the activation of the central nervous system, Complex visual-motor reactions "Choice reaction" (SPMR), and noise immunity (PU) to assess the functional mobility of the central nervous system and concentration of attention, tapping test (TT) to assess the strength of the nervous system (Huang et al., 2019; Burton et al., 2017). Statistical analysis of the results was carried out using the Statistica v. 7.0 application software package (StatSoft, USA). Descriptive statistical data analysis and correlation analysis were carried out (Kamenskaya, 2010).

\section{Results and Discussions}

\subsection{Results}

Sensorimotor response indicators are genetically determined and poorly trained, which allows them to be used in an objective assessment of the functional state of the central nervous system of the examined (Ignatova et al., 2019; Kraineva \& Shefer, 2017). The integral characteristics of the neurodynamic processes of the students of the survey cohort are summarized in Table 1. High-speed indicators of simple visual-motor reactivity of an individual can be considered as an integral characteristic of the human central nervous system since motor-tactile and visual analyzers are activated (Maltsev, 2018).

Table 1

Generalized indicators of sensorimotor reactions of pedagogical university students, $(n=111)$

\begin{tabular}{lccc}
\hline \multicolumn{1}{c}{ Indicator } & $M \pm m$ & Quartile (25-75) & $C V$ \\
\hline Median time value of the PZMR, ms & $227,25 \pm 2,83$ & $206,00-242,50$ & 13,1 \\
Standard deviation PZMR & $67,67 \pm 4,06$ & $47,97-78,46$ & 63,3 \\
The average value of the SZMR time & $370,92 \pm 4,38$ & $346,93-395,17$ & 12,4 \\
The standard deviation of the SZMR & $90,53 \pm 2,20$ & $74,43-98,79$ & 25,6 \\
The average value of the response time of & & & \\
noise immunity & $383,30 \pm 3,13$ & $359,20-400,40$ & 8,6 \\
Standard deviation of noise immunity & $79,52 \pm 2,57$ & $61,20-87,70$ & 34,1 \\
$\begin{array}{l}\text { Concentration of attention } \\
\text { Tapping test number of beats }\end{array}$ & $0,98 \pm 0,01$ & $0,90-1,00$ & 7,9 \\
$\begin{array}{l}\text { Indicator of the strength of the nervous } \\
\text { system, conl. units. }\end{array}$ & $198,42 \pm 2,09$ & $181,00-212,00$ & 11,1 \\
$\begin{array}{l}\text { Endurance level in points according to TT } \\
\text { indicators }\end{array}$ & $4,42 \pm 0,06$ & $4,00-4,70$ & 15,2 \\
\end{tabular}

A simple sensorimotor reaction allows us to assess the activation and speed of cerebral processing of simple sensory information. The obtained results of a simple visual-motor reaction of students correspond to the average level of the speed of functioning of the nervous system (the normative range of values is 193-233 ms. These results characterize the optimal performance of a specific cognitive activity within certain time limits. This indicator of cognitive performance of the students of the cohort of the survey within the framework of 
educational activities did not reveal signs of overstrain or fatigue of sensorimotor systems (Silakarma et al., 2021).

Slight variability in the average values of the PZMR indicator (CV PZMR does not exceed 15\%) and the quadratic deviation of the PZMR (SDPZMR corresponding to 50\% of the level of the normative range - 23-97 $\mathrm{ms}$ ) characterize the relative stability of the manifestation of sensorimotor reactions. The obtained values of these indicators indirectly characterize the balance of nervous processes and the stability of the manifestation of the functional state of the central nervous system in the majority of the examined cohort (Merlin, 2005).

Attention is drawn to the fact of the greatest variability of the coefficient of variation of the mean values of the standard deviations of the PZMR, SZMR, and PU in the studied groups of students (CV indicators vary from $25 \%$ to $63 \%$ ). This result probably reflects the adaptive-compensatory homeostatic mechanism of realization of the neurodynamic functions of the students' bodies under conditions of simple sensory load and sensory interference (Carchi et al., 2021).

Comparison of the average values of the SZMR of the surveyed students with the normative values (see Table 1), indicates an average level of severity of functional mobility of nervous processes. This reflects the effective possibility of neuronal switching of attention between different types of activity in the majority of the examined and the optimal speed of functional activity of the central nervous system of the examined contingent of students.

The average level of severity of the mobility of nervous processes characterizes the optimal switching of attention from one type of activity to another. This has been convincingly proved in the framework of neurophysiological research on the dynamic relationship of sensorimotor integration with cognitive systems of information analysis (Dikaya \& Naumova, 2014; Harris \& Lim, 2016; Ignatova et al., 2019).

\subsection{Discussions}

The analysis of the cognitive analytical-synthetic process of neuronal processing of sensory information can be objectively assessed by the indicator of the central delay time (the value of the difference between the indicators of the PZMR and the SZMR). The results obtained reflect the optimal duration of the process of analytical processing of sensory information in the cerebral cortex of the cohort of students (about 143 ms), which does not exceed $70 \%$ of the time range of the PZMR. The mechanisms of differentiation inhibition of conditioned reflex activity in all examined students provide improved cerebral processes, more accurate response to external stimuli, and acceleration of complex sensorimotor reactions. Functional lability is associated with the ability to respond on time to changes in external requirements, the speed of searching and updating the necessary information in memory, the speed of formation and optimization of activities in new conditions, the ability to inhibit irrelevant cognitive attitudes, etc.

The mobility of nervous processes is associated with the level of activation of the central nervous system and determines the speed of deployment of individual operations in the course of activity. The speed and tempo characteristics of the organization of activity, especially the maximum pace, are genetically determined and have a significant range of individual values that cannot be evaluated in the categories of "good-bad".

Noise immunity technique - characterizes the feature of attention that reflects a person's ability to resist the effects of background noise when perceiving an object. The obtained average values slightly exceed the SZMR indicators (no more than 3\%), which generally reflects the optimal neurodynamic features of the noise immunity of the students of the cohort of the survey. The concentration indicators correspond to the average values of the norm (0.8-1.0 units), which reflects the optimal ability for a long time to concentrate attention on the necessary object and perform a given activity regardless of the surrounding conditions in the students of the cohort of the survey.

The homeostatic characteristics of the complex sensorimotor response of students in the conditions of educational and professional activity in higher school are reflected in the correspondence of the average values of the standard deviation of the SZMR and PU to the normative range (69-113 ms) and relatively low values of the coefficients of variation (CV of the SZMR and PU $12.4 \%$ and $8.6 \%$, respectively). Thus, the obtained results of sensorimotor response reflect the optimal level of adaptive regulation of the cerebral component of activity in the majority of the surveyed students of a pedagogical university in the conditions of their educational and professional activity. The indicators of the standard deviation and coefficients of variation of sensorimotor reactions, reflecting the homeostatic level of neurophysiological regulation of

Belousova, N., Shefer, O., Semenova, M., Maltsev, V., Lebedeva, T., \& Korchemkina, Y. (2021). Neurodynamic predictors the effectiveness of cognitive activity of students ensuring healthy lifestyle. International Journal of Health 
activity, characterize the effective stabilization mechanisms of the formed functional system of the central nervous system of the students of the cohort of examination. The relative stability of cerebral processes with average functional mobility characterizes the formed functional system of a satisfactory conditioned reflex activity and acts as an objective predictor of the effectiveness of cognitive activity of the examined pedagogical university students.

The strength of nervous processes is a predictor of the stability of arbitrary regulation of cognitive processes to short-term dysfunctions arising under the influence of excessive emotional stress, stress, or fatigue. It is determined by the functional capabilities of the nervous system. Endurance is influenced by the level of development of coordination of movements, the strength of mental processes, and volitional qualities.

The tapping test indicators made it possible to characterize the manifestation of the strength of the nervous system as a criterion for the operability of neurons in conditions of urgent switching of excitatory and inhibitory processes. The average group values of the surveyed students in quantitative indicators of endurance of the nervous system, both in terms of the average number of strokes and in terms of ball endurance indicators, reflect an above-average level (standard 184-204 beats; 7-8 points, respectively), which characterizes the ability of the students of the cohort of the survey to perform any activity for a long time without reducing its effectiveness. At the same time, the average endurance indicators of the nervous system of the cohort of the examination correspond to the upper limit of the normative range, which will cut off the tendency to a high level of neuronal performance and stability of cerebral activity in conditions of cognitive activity.

The calculated indicator of the strength of the students' nervous system, which characterizes the ability to keep the pace of work at a certain level, corresponds to the average level. The learned results describe the optimal type of working capacity of individuals, moderate formation of fatigue due to mental or physical stress. Further research was aimed at identifying the relationship of the neurodynamic characteristics of the personality of the examined students with the indicators of a cognitive test assessing the level of mental performance. The summarized data are presented in Table 2 .

Table 2

Correlation matrix of the relationship of indicators of neurodynamics of the cognitive test, $(n=94)$

\begin{tabular}{lccc}
\hline \multirow{2}{*}{ Neurodynamic indicators } & \multicolumn{3}{c}{ Cognitive test scores } \\
\cline { 2 - 4 } & $\begin{array}{c}\text { Task completion } \\
\text { speed }\end{array}$ & $\begin{array}{c}\text { Overall performance } \\
\text { indicator }\end{array}$ & $\begin{array}{c}\text { Whipple Accuracy } \\
\text { Factor }\end{array}$ \\
\hline The average value of the speed of a simple & $-0,694$ & $-0,431$ & $-0,201$ \\
sensorimotor reaction (PZMR) & $\mathrm{p}<0,001$ & $\mathrm{p}<0,001$ & $\mathrm{p}=0,052$ \\
The average value of the time of the rate & $-0,377$ & $-0,203$ & - \\
of complex sensorimotor reaction (SPMR) & $\mathrm{p}<0,001$ & $\mathrm{p}=0,050$ & - \\
The average value of the time of the speed & $-0,282$ & - & - \\
of a complex sensorimotor reaction (noise & & - & - \\
immunity) & $\mathrm{p}=0,006$ & - & - \\
Tapping test number of beats & 0,302 & - & 0,258 \\
& $\mathrm{p}=0,003$ & - & $\mathrm{p}=0,012$ \\
Indicator of the strength of the nervous & - & - & - \\
system, conl. units. & - & - & - \\
Endurance level in points according to TT & 0,2503 & - & - \\
indicators & $\mathrm{p}=0,015$ & & - \\
\hline
\end{tabular}

Note: the table shows only reliable correlations, at $\mathrm{p}<0.05$.

\section{Conclusion}

In the course of the conducted research, we have identified correlations of neurodynamic indicators with parameters characterizing the success of cognitive activity of students. The results obtained reflect a highly reliable relationship between the speed indicators of cognitive activity and sensorimotor response. At the 
same time, the overall effectiveness of cognitive activity is moderately negatively associated with the indicators of central nervous system activation. And it is weakly negatively associated with an indicator reflecting the mobility of cerebral processes and the perfection of differentiation inhibition in the central nervous system. Accuracy indicators are inversely related to activation indicators and are directly proportional to the indicator of the strength of the nervous system.

The revealed characteristics of the functioning of the nervous system and their relationship with indicators of cognitive activity determine the optimal level of performance of educational tasks necessary for the qualitative development of the educational program in the context of the implementation of federal state educational standards of higher education. Studies of psychophysiological support of cognitive activity of students in the conditions of educational activity are significant for predicting the quality of education. An important aspect of further study is the need to determine objective valid indicative criteria describing the structure of a student's psychophysiological potential in specific conditions of educational and professional activity and corresponds to the main indicators of health quality recommended by SDG 3.

\section{Acknowledgments}

The work was carried out within the framework of the project "Fundamental study of individual differences in learning among students and schoolchildren using the methods of neuroscience and big data technologies".

Belousova, N., Shefer, O., Semenova, M., Maltsev, V., Lebedeva, T., \& Korchemkina, Y. (2021). Neurodynamic predictors the effectiveness of cognitive activity of students ensuring healthy lifestyle. International Journal of Health Sciences, 5(3), 531-541. https://doi.org/10.53730/ijhs.v5n3.2270 


\section{References}

Ahmadi, A., \& Tani, J. (2017). How can a recurrent neurodynamic predictive coding model cope with fluctuation in temporal patterns? Robotic experiments on imitative interaction. Neural Networks, 92, 3-16. https://doi.org/10.1016/j.neunet.2017.02.015

Andrews, S. C., Hoy, K. E., Enticott, P. G., Daskalakis, Z. J., \& Fitzgerald, P. B. (2011). Improving working memory: the effect of combining cognitive activity and anodal transcranial direct current stimulation to the left dorsolateral prefrontal cortex. Brain stimulation, 4(2), 84-89. https://doi.org/10.1016/j.brs.2010.06.004

Bayguzhin, P. A., \& Pracheva, A. A. (2014). Psychophysiological status of female students with different styles of cognitive activity. Modern problems of science and education, 3, 618.

Benson, D., Gain, A. K., \& Giupponi, C. (2020). Moving beyond water centricity? Conceptualizing integrated water resources management for implementing sustainable development goals. Sustainability Science, 15(2), 671-681.

Bidzan-Bluma, I., \& Lipowska, M. (2018). Physical activity and cognitive functioning of children: a systematic review. International journal of environmental research and public health, 15(4), 800.

Burton, C. E., Zhou, Y., Bai, Q., \& Burton, E. A. (2017). Spectral properties of the zebrafish visual motor response. Neuroscience letters, 646, 62-67. https://doi.org/10.1016/j.neulet.2017.03.002

Carchi, J. A. Y. ., Catagua, T. C. M. ., Rivera, D. G. B. ., Mera, V. B. ., \& Rosario, M. del . (2021). From beginner to expert, experience of the rotating nursing intern in pre-professional practice. International Journal of Health Sciences, 5(2), 111-117. https://doi.org/10.29332/ijhs.v5n2.1291

Chang, M. O., Peralta, A. O., \& Corcho, O. J. P. de. (2020). Training with cognitive behavioral techniques for the control of precompetitive anxiety. International Journal of Health \& Medical Sciences, 3(1), 29-34.

Dikaya, L. A., \& Naumova, M. I. (2014). Psychophysiological correlates of cognitive activity in motor-gifted schoolchildren. North Caucasian Psychological Bulletin, 12(1), 5-9.

Harris, A., \& Lim, S. L. (2016). Temporal dynamics of sensorimotor networks in effort-based cost-benefit valuation: early emergence and late net value integration. Journal of Neuroscience, 36(27), 7167-7183.

Hötting, K., \& Röder, B. (2013). Beneficial effects of physical exercise on neuroplasticity and $\begin{array}{llll}\text { cognition. Neuroscience \& } \quad \text { Biobehavioral } & \text { Reviews, 37(9), }\end{array}$ https://doi.org/10.1016/j.neubiorev.2013.04.005

Huang, I. J., Sirotkin, H. I., \& McElroy, A. E. (2019). Varying the exposure period and duration of neuroactive pharmaceuticals and their metabolites modulates effects on the visual motor response in zebrafish (Danio rerio) larvae. Neurotoxicology and teratology, 72, 39-48. https://doi.org/10.1016/j.ntt.2019.01.006

Ignatova, Y. P., Makarova, I. I., Yakovleva, K. I., \& Aksenova, A. V. (2019). Visual-motor reactions as an indicator of the functional state of the central nervous system. Ulyanovsk medical and biological journal, (3), 38-51.

Kamenskaya, V. G. (2010). Properties of the nervous system and temperament in the structure of individual typological characteristics of a person. Bulletin of the St. Petersburg University of the Ministry of Internal Affairs of Russia, 1(45), 202-209.

Khikmatullaeva, Khaydarov, N. K., Abdullaeva, M. B., \& Aktamova, M. U. (2021). Cognitive disorders in stroke. International Journal of Health \& Medical Sciences, 4(2), 202-207.

Kholodnaya, M. A., \& Khazova, S. A. (2017). The phenomenon of conceptualization as the basis of intellectual productivity and coping behavior. Psychological journal, 38(5), 5-17.

King, D. E., Mainous III, A. G., \& Geesey, M. E. (2007). Turning back the clock: adopting a healthy lifestyle in middle age. The American journal of medicine, 120(7), 598-603. https://doi.org/10.1016/j.amjmed.2006.09.020

Kraineva, S. V., \& Shefer, O. R. (2017). On the formation of very high competencies in bachelor's degree students using information and communication technologies. Scientific and Technical Information Processing, 44(2), 94-98.

Lachman, M. E., Agrigoroaei, S., Murphy, C., \& Tun, P. A. (2010). Frequent cognitive activity compensates for education differences in episodic memory. The American Journal of Geriatric Psychiatry, 18(1), 4-10. https://doi.org/10.1097/JGP.0b013e3181ab8b62

Laidra, K., Pullmann, H., \& Allik, J. (2007). Personality and intelligence as predictors of academic achievement: A cross-sectional study from elementary to secondary school. Personality and individual differences, 42(3), 441-451. https://doi.org/10.1016/j.paid.2006.08.001 
Litvinova, N. A. (2008). The role of individual psychophysiological characteristics of students in adapting to mental and physical activity. synopsis Diss.... Doc. of Biology, 3, 13.

Maltsev, V. P. (2018). Gender-specific characteristics of correspondence course students psychophysiological adaptation in the conditions of training activities. Azimuth of Scientific Research: Pedagogy and Psychology, $7(3(24)), 345-348$.

Maltsev, V. P., \& Suyundikova, Zh. T. (2019). Psychophysiological potential of adaptation of students of Russian and Kazakh ethnic groups to study at a pedagogical university. Psychology. Psychophysiology, 12(3), 72-82.

Mantrova, I. N. (2008). Methodological guide for psychophysiological and psychological diagnostics. Ivanovo, Russia: Neurosoft, $215 \mathrm{p}$.

McLaughlin, K. A., Borkovec, T. D., \& Sibrava, N. J. (2007). The effects of worry and rumination on affect states and cognitive activity. Behavior Therapy, 38(1), 23-38. https://doi.org/10.1016/j.beth.2006.03.003

Merlin, V. S. (2005). Psychology of individuality: Selected psychological works. MODEC, Moscow.

Riebe, D., Greene, G. W., Ruggiero, L., Stillwell, K. M., Blissmer, B., Nigg, C. R., \& Caldwell, M. (2003). Evaluation of a healthy-lifestyle approach to weight management. Preventive medicine,36(1), 45-54. https://doi.org/10.1006/pmed.2002.1126

Silakarma, D., Adiputra, N., Sudewi, A. A. R., \& Widiana, I. G. R. (2021). Brain gym application and brain vitalization exercises in Balinese dance movement improves cognitive functions, quality of live and decreasing BDNF level in elderly. International Journal of Health Sciences, 5(2), 135-150. https://doi.org/10.29332/ijhs.v5n2.1356

Tikhomirova, T. N. (2016). Cognitive foundations of individual differences in academic success: a structural and functional model: Abstract dis. ... doctors of psychological sciences. Psychological Institute of the Russian Academy of Education, Moscow, Russia, 50 p.

Widana, I.K., Sumetri, N.W., Sutapa, I.K., Suryasa, W. (2021). Anthropometric measures for better cardiovascular and musculoskeletal health. Computer Applications in Engineering Education, 29(3), 550561. https://doi.org/10.1002/cae.22202

Belousova, N., Shefer, O., Semenova, M., Maltsev, V., Lebedeva, T., \& Korchemkina, Y. (2021). Neurodynamic predictors the effectiveness of cognitive activity of students ensuring healthy lifestyle. International Journal of Health Sciences, 5(3), 531-541. https://doi.org/10.53730/ijhs.v5n3.2270 


\section{Biography of Authors}

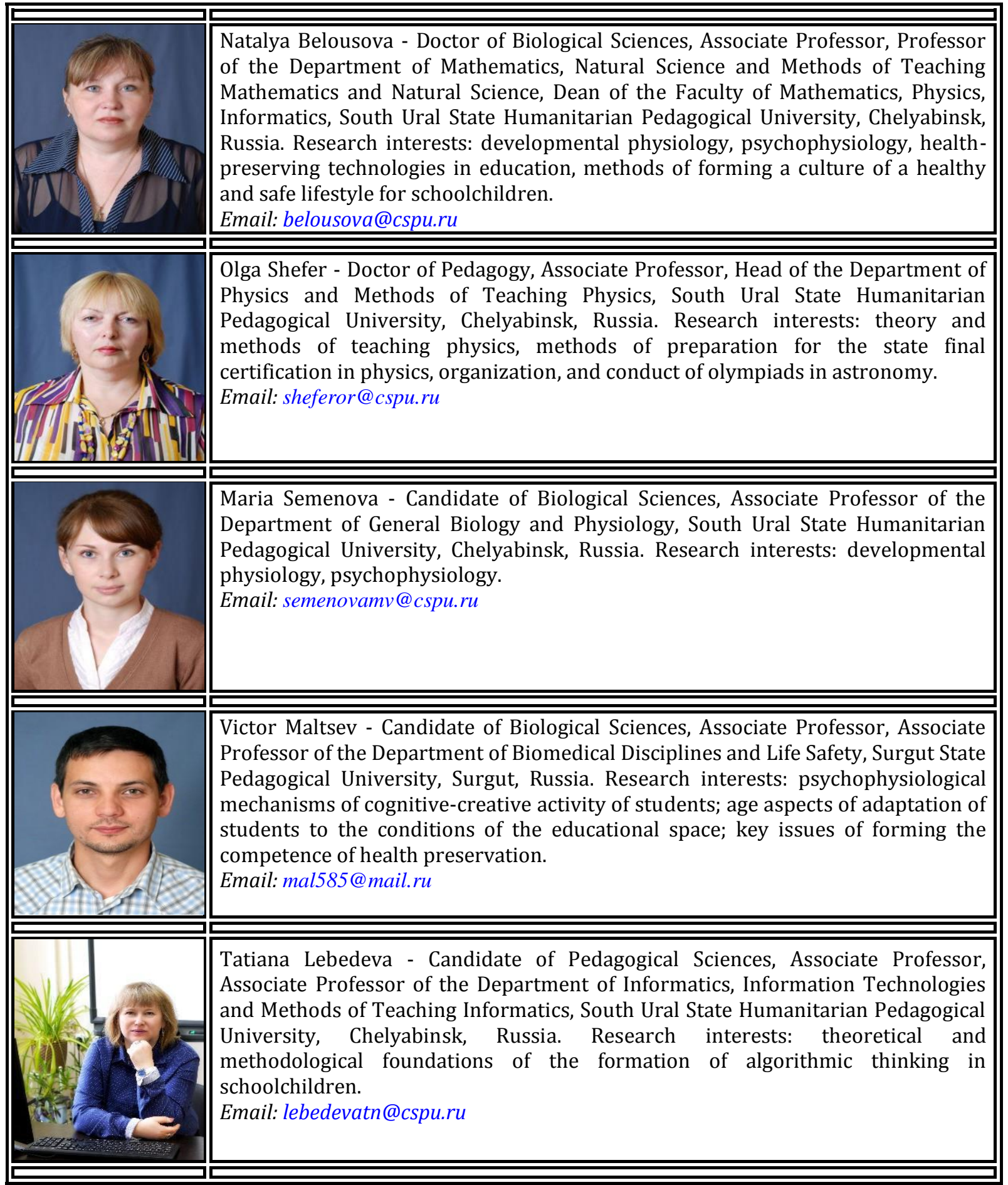




\begin{tabular}{|l|l|}
\hline & $\begin{array}{l}\text { Yuliya Korchemkina - Senior Lecturer of the Department of Informatics, } \\
\text { Information Technologies and Teaching Methods of Informatics, South Ural State } \\
\text { Humanitarian Pedagogical University, Chelyabinsk, Russia. Research interests: the } \\
\text { formation of information and analytical skills of students, the construction of } \\
\text { individual educational trajectories, psychophysiology. } \\
\text { Email: kjv_intser@mail.ru }\end{array}$ \\
\hline
\end{tabular}

Belousova, N., Shefer, O., Semenova, M., Maltsev, V., Lebedeva, T., \& Korchemkina, Y. (2021). Neurodynamic predictors the effectiveness of cognitive activity of students ensuring healthy lifestyle. International Journal of Health 